\title{
MULTILATERAL BARGAINING WITH CONCESSION COSTS
}

\author{
Guillermo Caruana, Liran Einav and Daniel Quint
}

CEMFI Working Paper No. 0415

September 2004

CEMFI

Casado del Alisal 5; 28014 Madrid

Tel. (34) 914290 551. Fax (34) 914291056

Internet: www.cemfi.es

We thank seminar participants at Universidad Complutense and the Second World Congress of the Game Theory Society in Marseille for helpful comments. The usual disclaimer applies. 
CEMFI Working Paper 0415

September 2004

\title{
MULTILATERAL BARGAINING WITH CONCESSION COSTS
}

\begin{abstract}
This paper presents a new non-cooperative approach to multilateral bargaining. We consider a demand game with the following additional ingredients: (i) There is an exogenous deadline, by which bargaining has to end; (ii) Prior to the deadline, players may sequentially change their demands as often as they like; (iii) Changing one's demand is costly, and this cost increases as the deadline gets closer. The game has a unique subgame perfect equilibrium prediction in which agreement is reached immediately and switching costs are avoided. Moreover, this equilibrium is invariant to the particular order and timing in which players make demands. This is important, as multilateral bargaining models are sometimes too sensitive to these particular details. In our context, players with higher concession costs obtain higher shares of the pie; their increased bargaining power stems from their ability to credibly commit to a demand earlier. We discuss how the setup and assumptions are a reasonable description for certain real bargaining situations.
\end{abstract}

JEL Codes: C72, C73, C78.

Keywords: Bargaining, Commitment, Switching costs.

Guillermo Caruana CEMFI caruana@cemfi.es
Liran Einav

Stanford University

leinav@stanford.edu
Daniel Quint

Stanford University

dquint@stanford.edu 


\section{Introduction}

Non-cooperative analyses of bargaining are sometimes criticized for being sensitive to the exact description of the extensive form. This concern is even more acute in the case of multilateral bargaining. In general, one needs to precisely specify the rules and timing for offers, counter-offers, vetoes, exit options, etc. All these details may have an impact on the outcome of the bargaining process. But this is at odds with the perception that negotiations are by nature very amorphous processes in which these details seem not to play such an important role. The relevant aspects have more to do with the ability to credibly commit to certain threats or promises. ${ }^{1}$ This paper tries to construct a model that abstracts from the former technical aspects and focuses more on the latter commitment opportunities.

Bargaining is normally studied using either the axiomatic approach introduced by Nash (1950), ${ }^{2}$ or the strategic approach, for which Rubinstein's (1982) seminal model is probably the most influential one. Rubinstein's alternating offer model is constructed for two players and has a unique equilibrium which implements Nash's axiomatic outcome in a non-cooperative way. The uniqueness of the equilibrium prediction, however, is lost when more players are introduced. Herrero (1985) and Haller (1986) show that any feasible agreement can be obtained in a subgame perfect equilibrium of the most natural extension of Rubinstein's bargaining protocol to three players. ${ }^{3}$ This is due to the veto power that each player possesses in those extensions: each player can void any agreement made by other players.

Krishna and Serrano (1996) illustrate that multilateral versions of Rubinstein's model can get around this problem and restore uniqueness by introducing an "exit option." After a proposal has been made, the exit option allows any player to accept his offered share, leave the bargaining table, and let the remaining $N-1$ players bargain over the rest of the pie. ${ }^{4}$ Such an exit option is a realistic description of some, but not all, bargaining

\footnotetext{
${ }^{1}$ See the Introduction of Perry and Reny (1993) for more on this issue.

${ }^{2}$ See Lensberg (1988) for a modern treatment of the multilateral case.

${ }^{3}$ See Sutton (1986) for a more general review.

${ }^{4} \mathrm{~A}$ similar result is obtained by Chae and Yang $(1988,1994)$ and Yang (1992). These papers achieve uniqueness by modeling multilateral bargaining as a sequence of bilateral agreements.
} 
situations. In legislative budget negotiations, for example, no party can secure funding until the entire budget is approved. Another feature of Krishna and Serrano's model (and of many other models of multilateral bargaining) is that when a player makes a proposal, he specifies the exact division of the pie among all parties. We will refer to this as an offer. An alternative approach, and the one used in this paper, is that parties can only express how much they demand for themselves, without stipulating the division among the others. In many situations this seems more realistic, as for example in the financing of public goods. ${ }^{5}$ Selten $(1992)$ and Winter $(1994 a, 1994 b)$ use the demand approach for the study of multilateral bargaining, but their outcomes depend on the exogenously pre-specified order of play. ${ }^{6}$

The model we present builds on the framework proposed in Caruana and Einav (2004). ${ }^{7}$ Bargaining must end before a fixed deadline, and players make demands sequentially in nearly continuous time. They can revise their demands as often as they like, but this is costly, and this cost increases as the deadline gets closer. The result of the bargaining process is successful only if the final demands are compatible with each other. Earlier demands, however, serve as a commitment mechanism, as reducing one's demand becomes increasingly expensive. This assumption imposes some aspect of irreversibility to past actions. This is similar to Admati and Perry's (1991) contribution game and to other papers that consider irreversible actions. ${ }^{8}$ All these papers, however, impose a very drastic switching cost structure: from the very beginning players are fully committed not to increase their demands from previously demanded levels (they face infinite costs of doing so), but are always free to decrease their demands. Meanwhile, our paper deals with finite concession costs that increase in a smooth way. In this manner, we can focus on the gradual process by which players achieve commitment. Moreover, as we show later on, all that is needed in the model is that the costs of conceding (reducing one's demand) increase over time; no structure is imposed on the costs of increasing one's demand. Thus, one can use our

\footnotetext{
${ }^{5}$ This distinction has no bite in bilateral situations, where a demand uniquely determines the offer to the other party.

${ }^{6}$ Morelli (1999) extends their framework to allow for an endogenously determined order, but still within a particularly defined protocol.

${ }^{7}$ Their framework is constructed to study commitment opportunities in two-player finite-action games.

${ }^{8}$ See, for example, Saloner (1987), Gale (2001), and Lockwood and Thomas (2002).
} 
setting to analyze both the case in which players cannot back out of previous promises, as in the case of irreversible actions; and the case in which one is always free to withdraw from previous promises. At first this latter case may seem striking: it is not obvious how commitment is achieved when players are not bound by previous offers. Note, however, that while demanding more appears to be costless, dynamically it is not. If one party fancifully makes an extremely high demand, he will later have to concede, incurring a cost.

The game has a unique equilibrium in which agreement is reached immediately and switching costs are avoided. Theorem 2 presents our main result: if players can revise their demands as often as they want, or more precisely, as the time between consecutive moves goes to zero, this unique equilibrium converges to a unique prediction of the split of the pie. It is in this sense that we claim that the model abstracts from the specific order and timing in which players get to play. In the case of symmetric players the model predicts equal shares for all players. In the case of asymmetric concession costs, players with higher concession costs obtain a higher share of the pie, as they are able to commit faster to a particular demand. ${ }^{9}$ Thus, in our setting higher concession costs imply higher bargaining power. While the capability of an organization to be flexible is generally considered a positive feature, in this setting it results in a loss of bargaining power. This suggests a rationale for rigid structures as bargaining devices. The difficulty of organizing a board of directors meeting, complex bureaucratic structures, posted prices, or having a clerk with no discretion at the shop counter are only some examples.

To gain intuition for the equilibrium outcome, consider two symmetric players bargaining over a dollar. We argue that it is perfectly credible for a player to hold firm to a demand of 50 cents. Just after the point in time at which concession costs increase above 50 cents, this player is committed to never reduce his demand below 50 cents. Thereby, just before this critical point in time, if the other player had started by asking "too much," he is better off conceding and scaling down his demand to 50 cents as well. In this manner, he will obtain positive payoffs, compared to payoffs of zero if no adjustment is made (resulting in no agreement). This argument can be made for both players, and thus, in equilibrium, each

\footnotetext{
${ }^{9}$ Muthoo (1996) presents a different two-player two-period bargaining model with commitment in which he obtains a similar qualitative result.
} 
starts by demanding 50 cents and never changes thereafter, avoiding any switching costs. The same logic extends to situations with more than two players, and when players are not symmetric.

We are aware, of course, that our dynamic structure does not adequately describe all bargaining situations. If the reader imagines a series of rounds at a bargaining table, it is difficult to have a general justification for the presence of increasing switching costs. Nevertheless, in our view, there are many relevant situations which are characterized by both an exogenous deadline and an increasing switching cost structure. Consider, for example, New York's bid to host the 2012 Olympic Games. The deadline is provided by the schedule set forth by the International Olympic Committee, which will select the host in July 2005. Towards this deadline, multiple interested parties in the U.S. - for example, New York City, New York State, the U.S. Federal Government, and various representatives of the private sector - will bargain over their relative contributions to improve New York's bid. Such bargaining may involve specific investments which cannot be fully recouped should the bid fail. To the extent that adding or subtracting from such investments is more costly as the July 2005 deadline gets closer, this situation may fit our framework. More generally, switching costs could represent actual costs of revising contracts (financial or legal), inconvenience, or reputational concerns. These are discussed in more detail in Section 5.

In Section 4 we present a different bargaining model with flow payoffs and constant (but small) switching costs, which is based on the game structure proposed by Lipman and Wang (2000). ${ }^{10}$ Such a situation better describes an ongoing bargaining relationship. For example, one can think of the daily division of labor within a household among its members, or of the decision on how to share the flow of profits among different members of a patent pool. While this model is of a distinct nature from the main model of the paper, it shares a similar equilibrium structure, which justifies its inclusion.

The rest of the paper proceeds as follows. Section 2 introduces the formal model. Section

\footnotetext{
${ }^{10}$ See also Marx and Matthews (2000), who analyze a finite-horizon public good game situation with flow payoffs.
} 
3 analyzes equilibrium play, proves the main result, and extends it to an asymmetric public good game. Section 4 discusses the extension of the basic model to the case of flow payoffs. Section 5 concludes by discussing in more detail how our setup and assumptions may relate to actual economic situations.

\section{The Model}

The model is an application of the framework proposed by Caruana and Einav (2004). Consider $N$ players who bargain over a pie of size 1 . Time is discrete. The game starts at $t=0$ and ends at a predetermined deadline $t=T$. Each player $i$ acts at a large but finite time grid $g_{i}=\left\{t_{1}^{i}, t_{2}^{i}, \ldots, t_{L_{i}}^{i}\right\}$ where $t_{l}^{i} \in[0, T]$ for all $l$ and $t_{l}^{i}<t_{m}^{i}$ if $l<m$. Players play sequentially, so $g_{i} \cap g_{j}=\emptyset$ for any $i \neq j$. When player $i$ acts at $t \in g_{i}$, he states some demand $a_{i}(t) \in A_{i}=[0,1]$. At every point in time all previous actions are common knowledge. For any point in time $t \in[0, T]$, denote the time of player $i$ 's next move by $\operatorname{next}_{i}(t)=\min \left\{t^{\prime} \in g_{i} \mid t^{\prime} \geq t\right\}$, and the time of player $i$ 's last move by $\operatorname{prev}_{i}(t)=\max \left\{t^{\prime} \in g_{i} \mid t^{\prime}<t\right\}$. Let also next $(t)=\min \left\{t^{\prime} \in \bigcup_{i} g_{i} \mid t^{\prime}>t\right\}$ be the time of the next move after $t$.

The first move by player $i$, taken at $t_{1}^{i}=\operatorname{next}_{i}(0)$, is costless. However, if he later (at $t>t_{1}^{i}$ ) changes his action, he has to pay a switching cost. If he concedes by changing his demand downwards, he pays a concession cost $c_{i}(t)$. If he demands more by changing his demand upwards, he pays demand $\operatorname{costs} d_{i}(t)$. We place no restriction on demand costs, except that $d_{i}(t)>0$ for any $t .{ }^{11}$ We impose the following assumptions on the concession cost function: $c_{i}(t)$ is strictly increasing in $t$ with $c_{i}(0)=0$ and $c_{i}(T)>1$. These assumptions capture the idea that conceding is very cheap early in the process, but prohibitively expensive just before the deadline.

Finally, we specify payoffs. Denote player $i$ 's actions by $\bar{a}_{i}=\left(a_{i}(t)\right)_{t \in g_{i}}$, all actions of all players by $\bar{a}=\left(\bar{a}_{i}\right)_{i \in N}$, and the final actions by all players by $a^{*}=\left(a_{i}\left(t_{L_{i}}^{i}\right)\right)_{i \in N}$. Player

\footnotetext{
${ }^{11}$ The assumption that demand costs, $d_{i}(t)$, are strictly positive is only made for convenience. Assuming weak inequality, i.e. $d_{i}(t) \geq 0$, does not change the equilibrium outcome and payoffs, but slightly complicates the analysis.
} 
$i$ 's payoffs are

$$
u_{i}(\bar{a})=\pi_{i}\left(a^{*}\right)-\sum_{\left\{t \in g_{i}-\left\{t_{1}^{i}\right\}: a_{i}(t)<a_{i}\left(\operatorname{prev}_{i}(t)\right)\right\}} c_{i}(t)-\sum_{\left\{t \in g_{i}-\left\{t_{1}^{i}\right\}: a_{i}(t)>a_{i}\left(\operatorname{prev}_{i}(t)\right)\right\}} d_{i}(t)
$$

where $\pi_{i}\left(a^{*}\right)$ is the usual demand game payoff

$$
\pi_{i}\left(a^{*}\right)=\left\{\begin{array}{ccc}
a_{i}^{*} & \text { if } \quad \sum a_{j}^{*} \leq 1 \\
0 & \text { if } \sum a_{j}^{*}>1
\end{array}\right.
$$

evaluated at the players' final demands.

The solution concept that we use is subgame perfect equilibrium (spe). While much of the analysis is carried for arbitrary grids, our main interest lies in games with fine grids, approximating continuous time. Thus, we define the fineness of the grid as $\varphi\left(g_{i}\right)=$ $\max \left\{t_{1}^{i}, t_{2}^{i}-t_{1}^{i}, t_{3}^{i}-t_{2}^{i}, \ldots, T-t_{L_{i}}^{i}\right\}$, denote the game grid by $g=\left\{g_{i}\right\}_{i=1}^{N}$, and its fineness by $\varphi(g)=\max _{i}\left\{\varphi\left(g_{i}\right)\right\}$. Our main result (Theorem 2) is a limiting result, when $\varphi(g)$ goes to zero.

\section{Results and Discussion}

\subsection{Subgame Perfect Equilibrium}

In this section we first solve for the equilibrium path of the game given a specific grid $g .{ }^{12}$ We show that on the equilibrium path an agreement is reached immediately and therefore switching never occurs. Each player's share of the surplus is uniquely determined by the game grid and the switching cost structure. Later we will focus on the limit of the equilibrium outcomes as the fineness of the grid tends to zero. In this manner we will be able to abstract from the grid and show that the equilibrium does not depend on the particular order in which players get to play.

Given a game with cost structure $\left\{c_{i}(\cdot), d_{i}(\cdot)\right\}_{i=1}^{N}$ and grid $g$, define

$$
t^{*} \equiv \max \left\{t \in \bigcup_{i} g_{i} \mid \sum_{j} c_{j}\left(\text { next }_{j}(t)\right) \leq 1\right\}
$$

\footnotetext{
${ }^{12}$ Strictly speaking, the equilibrium is not unique, due to the fact that players are sometimes indifferent between two actions. Still, as we show below, the important elements of the equilibrium, namely, actions on the equilibrium path and payoffs, are indeed unique.
} 
and

$$
\theta_{i} \equiv\left\{\begin{array}{cc}
c_{i}\left(\text { next }_{i}\left(t^{*}\right)\right) & \text { if } t^{*} \notin g_{i} \\
1-\sum_{j \neq i} c_{j}\left(\text { next }_{j}\left(t^{*}\right)\right) & \text { if } t^{*} \in g_{i}
\end{array}\right.
$$

Note that by construction $\sum_{j} \theta_{j}=1$ and that $c_{i}\left(t^{*}\right) \leq \theta_{i}<c_{i}\left(\operatorname{next}_{i}\left(\operatorname{next}\left(t^{*}\right)\right)\right)$ for player $i$ who moves at $t^{*} \in g_{i}$.

Our main result is that the equilibrium path of the bargaining game involves player $i$ demanding $\theta_{i}$ the first time he plays and never switching thereafter. Since the path of play does not depend on the costs of increasing one's demand, $d_{i}(t)$, we largely ignore these cost functions.

Much of our result is proved in the appendix. However, a few definitions and results which aid in the proof are instructive. Throughout, we abuse notation by describing each subgame by $(a, t)$, where $t \in \bigcup_{i} g_{i}$ is the point in time and $a \in[0,1]^{N}$ are the most recent demands made by each player. Strictly speaking, when a player is indifferent, his strategy may also depend on the history of play. We ignore this as all our statements about a subgame $(a, t)$ will hold for any history.

Definition 1 Player $i$ is flexible at $(a, t)$ if and only if $c_{i}\left(\right.$ next $\left._{i}(t)\right)<1$ $\sum_{j \neq i} \min \left(a_{j}, c_{j}\left(\right.\right.$ next $\left.\left._{j}(t)\right)\right)$.

In essence, a player is flexible if he could potentially earn a positive continuation payoff by revising his demand downwards. ${ }^{13}$ Note from these definitions that whether player $i$ is flexible depends on $t$ and $a_{-i}$, but not on $a_{i}$. At $t<t^{*}$ all players are flexible (this follows from the definition of $t^{*}$ ). Further, late in the game (after time $\bar{t} \equiv \max _{j}\left(c_{j}^{-1}(1)\right)$ ), no player is flexible.

Definition 2 A demand profile a is compatible if and only if $\sum_{j} a_{j} \leq 1$.

Clearly, an agreement is reached when final demands are compatible. We now give the following result, which will lead us to the equilibrium play.

\footnotetext{
${ }^{13}$ Once a switch is done, its costs are sunk; throughout the paper, we frequently consider players' payoffs net of previous switching costs, since at any point in the game, each player in equilibrium acts to maximize his continuation payoffs.
} 
Proposition 1 Consider a subgame $(a, t)$, in which there exists a player $i$ such that $a_{i} \leq$ $c_{i}\left(\right.$ next $\left._{i}(t)\right)$. If a is compatible or some player is flexible at $(a, t)$, then if player $i$ never switches and the other players play their equilibrium strategies, an agreement will be reached.

The proof is in the appendix. Proposition 1 implies that under the conditions stated above player $i$ is guaranteed a continuation value of at least $a_{i}$. This leads to the following result, and its subsequent implication.

Proposition 2 In any spe, every player $i$ must get a payoff of at least $\theta_{i}$.

Proof For any given player $i$, let $\tilde{t}=n \operatorname{ext}\left(t^{*}\right)$ if $t^{*} \in g_{i}$, and $\tilde{t}=t^{*}$ otherwise. Note that in either case, $\theta_{i}+\sum_{j \neq i} c_{j}\left(\right.$ next $\left._{j}(\tilde{t})\right) \leq 1$. Thus, if player $i$ demands any $a_{i}<\theta_{i}$ at time $\tilde{t}$ then all players $j \neq i$ will be flexible. Since $a_{i}<\theta_{i} \leq c_{i}\left(\right.$ next $\left._{i}(\tilde{t})\right)$, Proposition 1 holds, so player $i$ is guaranteed agreement without switching. Thus, for any $\epsilon>0$, the strategy "Demand $\theta_{i}-\epsilon$ at the beginning and never switch" earns a payoff of $\theta_{i}-\epsilon$. Now, if in equilibrium player $i$ earned less than $\theta_{i}$ then, for $\epsilon$ sufficiently small, the previous strategy would represent a profitable deviation.

Theorem 1 In any spe of this game, every player demands $\theta_{i}$ in the first round and never switches on the equilibrium path.

Proof Since $\sum_{j} \theta_{j}=1$, any other equilibrium play would result in a payoff of less than $\theta_{i}$ for some player $i$, violating Proposition 2.

The main qualitative features of the equilibrium are the following: (i) In order to avoid switching costs, an agreement is achieved immediately; (ii) The higher the concession costs of one player, the higher the share of the pie he obtains. Having higher costs allows a player to commit not to lower his demand any longer while other players are still flexible to do it. Thus, the source of bargaining power in this model stems from the ability to commit to certain demands, which is achieved through a higher concession cost technology; (iii) Even though the value of $t^{*}$ is determined endogenously, once it is known and fixed 
one can realize that the solution of the game is invariant to changes to the concession cost functions $c_{i}(\cdot)$ at any $t \neq n e x t_{i}\left(t^{*}\right)$, as well as to changes in the players' costs of increasing their demands. Thus, the relative flexibility of different players does not matter but on the neighborhood of $t^{*}$.

\subsection{The Main Result and Its Implications}

We can now abstract from the specific grid chosen and think generally on situations in which players can revise their demands as often as they want. We study this case by taking limits on the fineness of the grid. In other words, we consider the distance between any two consecutive decisions by the same player going to zero. As one can notice, we only need to add the requirement that the concession cost functions are continuous for the result to hold.

Theorem 2 If $c_{i}(t)$ is continuous for all $i$, then taking $\varphi(g) \rightarrow 0$, the limit of the equilibrium path exists and converges to players demanding $\theta_{i}=c_{i}\left(t^{*}\right)$ throughout the game, where $t^{*}$ solves $\sum_{j} c_{j}\left(t^{*}\right)=1$.

Note that this outcome is independent of the order in which the players get to play. It is in this sense that we argue that this multilateral bargaining model is robust to changes in the protocol. For the rest of this section, we ignore the grid and focus on the limit case, when $\varphi(g) \rightarrow 0$.

Next we consider a few special cases which lead to simple comparative statics and provide intuition for the forces at play. First, we consider the family of cost functions $c_{i}(t)=\lambda_{i} c(t)$. That is, all players share the same concession cost technology, up to a multiplicative constant. In this case $\theta_{i}=\frac{\lambda_{i}}{\sum_{j} \lambda_{j}}$. Thus, the vector of $\lambda$ 's is a sufficient statistic for the equilibrium allocation, and the players receive shares of the pie proportional to their $\lambda_{i}$ 's. That is, the higher the (relative) concession costs, the bigger the share of the pie obtained. Moreover, in this case the allocation is independent of the choice of the cost function $c(t)$ and of the actual size of the pie. Interestingly, this invariance with respect to the size of the pie does not hold if one considers more general cost functions. Recall that 
the solution depends only on the relative value of the cost functions at a particular point, $t^{*}$. If the size of the pie is $k$, then $t^{*}$ would be defined by $\sum_{j} c_{j}\left(t^{*}\right)=k$. Thus changes in the size of the pie result in a different $t^{*}$, which in principle could result in different relative costs.

Consider next the case in which all players share the same concession cost technology but differ in their marginal valuation for the pie. That is, if there is an agreement and the shares are $a$, player $i$ values it $\pi_{i}(a)=\gamma_{i} a_{i}$. In other words, what we are considering now are (linear) changes in the utility bargaining sets. It is easy to see that this is equivalent to the case in which all players value the pie equally but have cost functions $c_{i}(t)=$ $c(t) / \gamma_{i}$. Thus, the outcome of the bargaining process would deliver a higher share of the pie to those who value the object less, as these are the ones who will get committed more quickly. Graphically, the solution of the game would be the point on the Pareto frontier that intersects with the ray with direction $\theta$. If players have the same cost technology, the solution would be the egalitarian one, ${ }^{14}$ independent of the values of the $\gamma_{i}$ 's.

Finally, we consider the impact of introducing a discount factor into the model. Suppose that each player discounts the future at a discount rate of $\delta_{i}$; that is, costs incurred at time $t$ are discounted by $\delta_{i}^{t}$, and the agreement by $\delta_{i}^{T}$. By dividing each player's utility function $u_{i}$ by $\delta_{i}^{T}$, it is clear that this model is equivalent to one without discounting where each player's concession costs are $\tilde{c}_{i}(t)=\delta_{i}^{t-T} c_{i}(t)$. Thus, introducing discounting is equivalent to a change in the cost function. Since $\delta_{i}^{t-T}$ is decreasing in $\delta_{i}$, more patient players have less bargaining power. Since players at any point in time compare their switching costs (incurred now) to their eventual payoff gains (received later), a lower valuation of the latter makes switching costs effectively higher, giving less patient players more commitment power. Since bargaining shares depend on the relative sizes of $\delta_{i}^{t^{*}-T} c_{i}\left(t^{*}\right)$, this effect is more pronounced for earlier $t^{*}$, corresponding to a smaller surplus being divided. Of course, since less-patient players discount their consumption more steeply, their bargaining advantage does not lead them to a higher utility level.

\footnotetext{
${ }^{14}$ That is, all the players receiving the same utility, not the same share of the pie.
} 


\subsection{The Public Good Game}

In the introduction we used the leading example of different parties trying to jointly fund New York's bid to host the 2012 Olympic Games. Below we show how our previous result is useful in analyzing this sort of public good problem as well.

Public good games are strategically very similar to bargaining games. Consider the following payoff structure. $N$ players have to simultaneously decide how much to contribute towards a public good. The public good is provided only if a minimal amount, which we normalize to 1 , is collected. If each player contributes $b_{i} \in[0,1]$, payoffs are

$$
\pi_{i}(b)=\left\{\begin{array}{ccc}
v_{i}-b_{i} & \text { if } \quad \sum b_{j} \geq 1 \\
0 & \text { if } \quad \sum b_{j}<1
\end{array}\right.
$$

where $v_{i}$ is player $i$ 's valuation of the public good.

We can reinterpret this model as a bargaining one in which demands are $a_{i}=v_{i}-b_{i}$ and the size of the pie is $\sum v_{i}-1$. The only difference is that now demands are constrained to lie in the interval $a_{i} \in\left[v_{i}-1, v_{i}\right]$ because contributions cannot be negative. As before, higher concession costs result in a higher share of the pie, which corresponds to lower contributions. Since equilibrium demands $a_{i}^{*}=v_{i}-b_{i}^{*}$ are derived directly from the cost structure, a player's contribution is increasing in his own valuation of the public good.

One new feature is that when asymmetries among players become sufficiently acute the equilibrium results in a corner solution. This happens when the solution to the analogous bargaining game involves a demand $a_{i}^{*}$ which is greater than $v_{i}$. Since we restrict contributions to be non-negative, player $i$ would demand in equilibrium $v_{i}$, which corresponds to a contribution of $b_{i}=0$. If a player's relative interest in the public good is sufficiently low, or his concession costs sufficiently high, he can commit not to contribute at all, forcing others to do all the funding. The actual division among the active contributors could be computed by analyzing the reduced game in which the free riders are ignored. 


\section{Flow Payoffs with Constant Switching Costs}

In this section, we extend our analysis to a different bargaining model. While its underlying economic structure is very different from the one studied before, its analysis is quite similar. The model builds on the framework studied by Lipman and Wang (2000). There are two key differences from the previous model. First, rather than a one-shot payoff in the end of the game, players collect a flow of payoffs from their bargaining interaction. Second, switching costs are small and constant over time.

Patent pools may provide a good application for this setup. Suppose that two firms held complementary patents which could only be used together. Should they agree on a way to share revenues, they can collect a flow of revenues as the technology is used; as long as they disagree, nobody can use the patents, so potential revenues are lost. In this context, switching costs can be arbitrarily small, so the additional lawyers' fees of re-drafting an agreement would suffice.

As before, players make demands on a finite grid $g$ in the interval $[0, T]$, and we are mainly interested in grids that are sufficiently fine. When player $i$ plays he decides on his demand $a_{i} \in[0,1]$. If he changes his demand from his previous level, he pays a small switching cost $\epsilon_{i}>0 .{ }^{15}$ In between two decision periods demands are fixed. Thus, flow payoffs are the standard payoffs of the demand game with respect to the most recent announcements made. With some abuse of notation, we denote $a_{i}(t)=a\left(\operatorname{prev}_{i}(t)\right)$ for $t \notin g_{i}$ and obtain the final payoffs as

$$
u_{i}\left(\bar{a}_{i}, \bar{a}_{j}\right)=\int_{0}^{T} \pi_{i}\left(a_{i}(\tau), a_{j}(\tau)\right) d \tau-\sum_{\left\{t \in g_{i}-\left\{t_{1}^{i}\right\}: a_{i}(t) \neq a_{i}\left(\operatorname{prev}_{i}(t)\right)\right\}} \epsilon_{i}
$$

where $\pi_{i}(a)$ is given by equation $(2) .{ }^{16}$

This setup is closely related to our main model. Loosely speaking, here one compares the constant switching costs, $\epsilon_{i}$, to the remaining future payoffs, $(T-t) \pi_{i}$. Meanwhile, in

\footnotetext{
${ }^{15}$ To simplify notation, we assume throughout this section that switching demand upwards and downwards has the same cost. This is not important. As before, only concession costs will matter, so we could assume any arbitrary non-negative structure on the cost of switching the demand upwards.

${ }^{16}$ For completeness, one may assume that $\pi_{i}=\pi_{j}=0$ before both players make their very first announcements (i.e. for all $\left.t<\max \left(t_{1}^{i}, t_{2}^{i}\right)\right)$.
} 
the main model the relevant comparison is made between the final payoffs of $\pi_{i}$ and the increasing switching costs of $c_{i}(t)=\frac{\epsilon_{i}}{T-t}$. This explains why the analysis is similar. There is an important difference, however, between the two models. In the main model each player only cares about his own actions and his opponents' final actions. Here, each player's payoffs depend on the whole sequence of his opponents' interim actions, as these determine the flow-payoffs. This makes the analysis of the flow-payoff case more complicated. For this reason, we restrict our attention to the case of two players.

As the proof is quite similar to the one of Theorem 2, we state below only the main result and relegate all the intermediate results to the appendix.

Theorem 3 Given switching costs $\epsilon_{i}, \epsilon_{j}$, the limit of the equilibrium path of the flow-payoff game, taking $\varphi(g) \rightarrow 0$, exists and converges to players constantly demanding $a_{i}=\frac{\epsilon_{i}}{\epsilon_{i}+\epsilon_{j}}$ throughout the game.

The first step of the proof is similar to the two-player version of our main model. The critical point in time, $t^{*}$, is now equal (in the limit) to $T-\epsilon_{i}-\epsilon_{j}$. After this point, the remaining continuation payoffs of the game are less than $\epsilon_{i}+\epsilon_{j}$, so in equilibrium we cannot expect both players to switch after $t^{*}$. This allows each player to obtain his share of the pie, $a_{i}=\frac{\epsilon_{i}}{\epsilon_{i}+\epsilon_{j}}$, from then on. Unlike our original model, however, this is not enough to finish the proof. Because of the flow payoffs, we need to argue that these shares are obtained throughout the game, and not only in the end. To do so, we use induction on the game tree, and show that by demanding $\frac{\epsilon_{i}}{\epsilon_{i}+\epsilon_{j}}$ at any point, player $i$ can guarantee an agreement almost immediately.

As before, higher switching costs imply higher commitment and higher bargaining power. Therefore, it allows a player to obtain a higher share of the pie. One should note that these results hold even when switching costs are arbitrarily small. As long as the players can change their demands sufficiently often, the absolute level of switching costs does not matter; only the relative costs do.

Finally, let us point out why the result of Theorem 3 does not extend to $N$ players. The key point at which the proof fails is when one argues that a flexible player finds it 
profitable to switch down and lock himself into a compatible demand profile. ${ }^{17}$ With flow payoffs this may not be profitable anymore. In principle, such a switch can induce other opponents to change their own demands as well. This may temporarily result in a period of disagreement. This amount of time, even though short, may be enough to make the original switch not profitable.

\section{Concluding Remarks}

We have presented a new bargaining model in which an arbitrary number of players negotiate in nearly continuous time, subject to an exogenous deadline and increasing concession costs. We find that as the time between "rounds" decreases toward zero, our model gives a unique equilibrium prediction which is invariant to the order and exact timing of the players' moves. Delay or disagreement never occur on the equilibrium path, and higher shares go to players with higher concession costs, as they are able to credibly commit to higher demands. As already emphasized, only concession costs matter. Whether concessions are fully reversible or completely irreversible has no impact on the results.

As we highlighted before, there are three key features that describe our model: (i) Players must reach an agreement by some external deadline or forfeit the entire prize; (ii) Players, in a sequential manner, have many opportunities to change their minds; (iii) The costs of conceding and switching to a lower demand, even a nearby one, are significant, and increase over time.

The second feature is of a more technical nature. We are simply imposing a particular set of rules on how players are allowed to express their demands. As was our goal, we show that these assumptions on the timing and order of moves have no real implications. The important aspect is to ensure the ability of players to react quickly to other players' moves. The other two assumptions are more economic in nature, and deserve a more careful discussion of their applicability.

Examples of bargaining with a fixed deadline are common. During bankruptcy pro-

\footnotetext{
${ }^{17}$ This happens, for example, in the last paragraph of the proof of Proposition 1.
} 
ceedings, management may face a court-assigned deadline by which they must reach new wage agreements with multiple unions or face liquidation. In the Olympic bid example discussed above, multiple parties must agree to provide costly services in order to submit a potentially winning bid. This process is clearly subject to an external deadline. Another example in which these deadlines are ubiquitous is in major sports. Multi-team trades are frequent and there are rules imposing specific deadlines to player trades.

Crawford (1982) presents a theory of impasse in bargaining which assumes that switching costs are not only substantial, but also stochastic and unknown at the time the demand is made. Thus, parties may attempt to commit to incompatible demands, and in the event that the realization of both sides' switching costs are high, neither side can back down and an impasse occurs. In our model, switching costs are substantial, but known ahead of time, so impasses do not occur on the equilibrium path.

Real-world examples of bargaining with literal switching costs may not seem as natural. But, without any commitment, demands or offers can be seen as simple cheap talk, or be subject to future renegotiation. Thus, an offer only becomes credible once it becomes costly to change it. In the Olympic bid example, parties may begin spending money (hiring architects or planners, scheduling contractors, even beginning construction) to show the seriousness of their offers. Once these steps are taken, changing plans would likely incur additional costs. In the presence of a deadline, such costs are likely to be higher as the deadline approaches. In addition, in many complex situations, there are various frictional costs (lawyers' fees, court fees, costs of preparing a new proposal) associated with each new offer submitted.

One can also interpret switching costs in a more metaphoric way, or in the context of an (unmodeled) larger game. In a wage negotiation setting, each side may be aware that by retreating from their demands, they sacrifice their reputation for being a tough negotiator, hurting them in future negotiations and thus imposing a cost to switching. This interpretation is especially appealing in negotiations in which parties choose to make public statements in the media as a way to tie their hands to future concessions. Union leaders, for instance, may advertise their demands publicly, essentially staking their credibility on 
achieving the outcome they have promised. In a situation where sports teams try to arrange a multi-team trade, noisy communication could lead to a situation where changing one's demand leads to a positive probability that the deal falls through. Many of these features are likely to become more salient when changes-of-mind happen late in the game, justifying our assumption that switching costs increase.

Thus, aside from giving a unique robust prediction in a multilateral bargaining game, we feel that the proposed model is based on assumptions which may provide a reasonable approximation of certain real-world bargaining situations. 


\section{Appendix}

\section{A Proof of Proposition 1}

We now build up a proof of Proposition 1 through a series of lemmas.

First, similar to the definition of flexible in the text (Definition 1), we define the following:

Definition 3 Player $i$ is locked at $(a, t)$ if and only if $c_{i}\left(\right.$ next $\left._{i}(t)\right)>1$ $\sum_{j \neq i} \min \left(a_{j}, c_{j}\left(\operatorname{next}_{j}(t)\right)\right)$.

As we will establish in Lemma 3, a player is locked when, subject to other players playing equilibrium strategies, he prefers disagreement to further concessions. At $t \leq t^{*}$, no player is locked, and late in the game, after time $\bar{t} \equiv \max _{j}\left(c_{j}^{-1}(1)\right)$, all players are locked.

Lemma 1 Given any $(a, t)$, the final demands arising in any equilibrium of the continuation game starting at $(a, t), a^{*}$, satisfy $a_{i}^{*} \geq \min \left(a_{i}, c_{i}\left(\right.\right.$ next $\left.\left._{i}(t)\right)\right)$ for all $i$. Moreover, if $a$ is compatible or at least one player switches, then $a^{*}$ is compatible.

Proof If a player switches downward then he must at least recoup his switching costs $\left(a_{i} \geq c_{i}\left(\right.\right.$ next $\left.\left._{i}(t)\right)\right)$, otherwise he would have been better off not switching and receiving at least a continuation value of zero (net of switching costs incurred prior to $t$ ). ${ }^{18}$ If a player switches only upward then $a_{i}^{*} \geq a_{i}$. Since switching costs are positive in either direction, a switch is rationalized only if $a^{*}$ is compatible. If $a$ is compatible and nobody switches, then $a^{*}=a$ is compatible.

Lemma 2 Let $a^{*}$ be the spe outcome of the subgame beginning at $(a, t)$. If $a^{*}$ is compatible then $a_{i}^{*} \leq 1-\sum_{j \neq i} \min \left(a_{j}, c_{j}\left(\right.\right.$ next $\left.\left._{j}(t)\right)\right)$ for all $i$.

\footnotetext{
${ }^{18}$ Given that once a switch is done, its costs are sunk, all the calculations are made net of those costs. Even though we do not mention again, all coming arguments are performed in net terms.
} 
Proof This follows directly from the fact that if $a^{*}$ is compatible then $a_{i}^{*} \leq 1-\sum_{j \neq i} a_{j}^{*}$, and Lemma 1.

Lemma 3 If player $i$ is locked at $(a, t)$, in equilibrium he will not switch downwards thereafter.

Proof If $i$ switched on equilibrium, the final demand profile $a^{*}$ would be compatible (Lemma 1), implying that $a_{i}^{*} \leq 1-\sum_{j \neq i} \min \left(a_{j}, c_{j}\left(\right.\right.$ next $\left.\left._{j}(t)\right)\right)<c_{i}\left(\right.$ next $\left._{i}(t)\right)$ (Lemma 2). But this would imply that player $i$ 's continuation payoff is negative.

Lemma 4 If there exists a player who is flexible at $(a, t)$ then any player who is not flexible must have $a_{k}<c_{k}\left(\right.$ next $\left._{k}(t)\right)$.

Proof Let $i$ be a player who is flexible and $k$ the player who is not flexible. Then

$$
\min \left\{a_{i}, c_{i}\left(\text { next }_{i}(t)\right)\right\} \leq c_{i}\left(\text { next }_{i}(t)\right)<1-\sum_{j \neq i} \min \left\{a_{j}, c_{j}\left(\text { next }_{j}(t)\right)\right\}
$$

and rearranging,

$$
\min \left\{a_{k}, c_{k}\left(\operatorname{next}_{k}(t)\right)\right\}<1-\sum_{j \neq k} \min \left\{a_{j}, c_{j}\left(\operatorname{next}_{j}(t)\right)\right\}
$$

If $a_{k} \geq c_{k}\left(\right.$ next $\left._{k}(t)\right)$ then the left-hand side above is $c_{k}\left(\right.$ next $\left.t_{k}(t)\right)$ and the assumption that $k$ was not flexible is violated.

Lemma 5 If none of the players is flexible at $(a, t)$ then any upward switch leaves demands compatible.

Proof Suppose player $j$ moves at $t$. Then $c_{j}\left(\right.$ next $\left._{j}(n \operatorname{next}(t))\right)>c_{j}\left(\right.$ next $\left._{j}(t)\right)$. If $a_{j}$ also increases at time $t\left(\right.$ to $\left.a_{j}^{\prime}\right)$ then $\min \left(a_{j}^{\prime}, c_{j}\left(\right.\right.$ next $\left.\left._{j}(n \operatorname{ext}(t))\right)\right)>\min \left(a_{j}, c_{j}\left(\right.\right.$ next $\left.\left._{j}(t)\right)\right)$. In that case, all players $i \neq j$ who were not flexible become locked. Since $c_{j}\left(\right.$ next $\left._{j}(\operatorname{next}(t))\right)>$ $c_{j}\left(\right.$ next $\left._{j}(t)\right)$, player $j$ also becomes locked. Thus, if player $j$ increases his demand when no players are flexible, all players are locked after his move, so by Lemma 3, nobody switches down in the future; if he leaves $a$ incompatible then no agreement is reached, giving $j$ negative continuation value. 
Lemma 6 Consider the continuation game $(a, t)$ where player $i$ moves at $t$. If $a_{i} \leq c_{i}(t)$, a is not compatible, and no player is flexible then in equilibrium, player $i$ does not switch at $t$.

Proof By Lemma 5, player $i$ does not switch upwards. If $i$ is not flexible, $c_{i}(t) \geq 1-$ $\sum_{j \neq i} \min \left(a_{j}, c_{j}\left(n e x t_{j}(t)\right)\right)$, so by Lemma $2, a_{i}^{*} \leq c_{i}(t)$. Since $a_{i} \leq c_{i}(t)$, if $i$ switches downwards at $t$, he incurs a cost $c_{i}(t)$, and either receives $a_{i}^{*}<c_{i}(t)$, or receives $a_{i}^{*}=c_{i}(t)$ but incurs a cost $d_{i}\left(t^{\prime}\right)$ of switching upwards later. In either case, the continuation payoff is negative.

We are now ready to prove Proposition 1 . The proof is by induction on $t$. Late in the game, no players are flexible. At the latest point in the game grid, $t=\max \left(\tau \mid \tau \in \cup g_{i}\right)$, if $a$ is incompatible, the proposition is vacuously true. Suppose $a$ is compatible. If $i$ moves at $t$ and does not switch, the game ends with compatible demands. If $j \neq i$ moves at $t, j$ will not switch to incompatible demands (doing so would give him negative continuation value), so the game ends in agreement with $a_{i}^{*}=a_{i}$.

Now suppose the proposition is proven for all $t^{\prime} \geq n \operatorname{ext}(t)$; we prove it for $t$. There are two cases:

1. First, suppose player $i$ moves at $t$. If $a$ is compatible then by not switching, $i$ leaves $a$ compatible and the induction assumption proves the proposition. Suppose $a$ is not compatible but some player other than $i$ is flexible. Since $a_{i} \leq c_{i}\left(\right.$ next $\left._{i}(t)\right)$, if $i$ does not switch, $\min \left(a_{i}, c_{i}\left(\right.\right.$ next $\left.\left._{i}(\cdot)\right)\right)$ does not change, so that player remains flexible so the induction assumption proves the proposition. Finally, if only player $i$ is flexible then by Lemma 4 and the definition of flexible

$$
c_{i}(t) \leq 1-\sum_{j \neq i} \min \left(a_{j}, c_{j}\left(\operatorname{next}_{j}(t)\right)\right)=1-\sum_{j \neq i} a_{j}
$$

Then since $a_{i} \leq c_{i}(t) \leq 1-\sum_{j \neq i} a_{j}, a$ is compatible, in which case we have already proven the proposition.

2. Now suppose player $j \neq i$ moves at $t$. If after $j$ 's move, the new demands are compatible or some player is flexible, the induction assumption proves the proposition. 
Thus, we only need consider the case where after $j$ 's move, no player is flexible and demands are incompatible. First, suppose $j$ switches at time $t$. Assume that thereafter player $i$ does not switch and the other players play equilibrium strategies, and consider all the times that player $i$ moves after $t$. If $a$ is compatible or some player is flexible at any of these times, then the induction assumption proves the proposition. If $a$ is incompatible and no player is flexible at all of these times, then by Lemma 6, player $i$ is playing his equilibrium strategy by not switching. Then starting at $(a, t)$, player $j$ switches and every player plays his equilibrium strategy after $t$; by Lemma 1 , an agreement is reached.

We are left with the case where $j$ does not switch at $t$ but after $j$ 's move, all players are not flexible and $a$ is not compatible. As we argued above, if these conditions do not remain at each of player $i$ 's subsequent moves, then the induction assumption proves the proposition; if they do, then all players are playing equilibrium strategies, so player $j$ 's inaction led to a subgame where, in equilibrium, agreement is not reached, giving a continuation payoff of 0 to player $j$. If $j$ was the only player flexible at $t$, then switching down to $a_{j}^{*}=1-\sum_{k \neq j} a_{k}>c_{j}(t)$ would have locked all players and led to positive continuation payoff. If $j$ was not flexible at $t$, then some other player was; since by Lemma $4, a_{j}<c_{j}(t)$, not switching could not have changed another player's flexibility, so by the induction assumption, an agreement would have been reached. Finally, if $j$ and another player were flexible at $t$, then $j$ switching down to $c_{j}(t)+\epsilon$ would have left the other player flexible for $\epsilon$ small enough; since $c_{j}(t)+\epsilon<c_{j}\left(\right.$ next $_{j}($ next $\left.(t))\right)$, player $j$ would have been ensured agreement without switching again (by the induction assumption) for a continuation payoff of $\epsilon>0$.

Thus, regardless of who moves at $t$, the proposition is proved. 


\section{B Proof of Theorem 3}

We use a similar approach to the one we use to prove Theorem 2. Given a grid $g$, we define

$$
t^{*}=\max \left\{t \mid \sum_{j} \frac{\epsilon_{j}}{T-n e x t_{j}(t)} \leq 1\right\}
$$

and

$$
\theta_{i}=\left\{\begin{array}{cl}
\frac{\epsilon_{i}}{T-n e x t_{i}\left(t^{*}\right)} & \text { if } t^{*} \notin g_{i} \\
1-\theta_{j} & \text { if } t^{*} \in g_{i}
\end{array}\right.
$$

As before, we will abstract from the grid and show through a series of lemmas and propositions that in equilibrium players immediately demand $\theta_{i}$ and do not change these demands thereafter. We need to introduce some more notation. We will refer to

$$
a_{i}^{*}=\frac{1}{T-t} \int_{t}^{T} a_{i}(\tau) d \tau
$$

as the average continuation demand. This does not need to coincide with average payoffs, as it may be the case that the demand profiles are not compatible, so at least temporarily no agreement is reached.

Lemma 7 Given any $(a, t)$, the average demands arising in any equilibrium of the continuation game starting at $(a, t), a^{*}$, satisfy $a_{i}^{*} \geq \min \left(a_{i}, \frac{\epsilon_{i}}{T-t}\right) \forall i$.

Proof Consider the equilibrium path of $(a, t)$. If player $i$ never switches on equilibrium then $a_{i}^{*}=a_{i}$. If player $i$ switches in equilibrium (at time $t$ or after), he must obtain nonnegative payoffs. This can only be possible if $\epsilon_{i} \leq(T-t) a_{i}^{*}$, otherwise he cannot hope to cover his switching costs. Therefore, we obtain that $a_{i}^{*} \geq \min \left(a_{i}, \frac{\epsilon_{i}}{T-t}\right)$.

Proposition 3 Given $(a, t)$ such that $a_{i} \geq \theta_{i}$ and $t>$ next $_{i}\left(t^{*}\right)$, player $j$ never switches in any equilibrium of the continuation game $(a, t)$.

Proof By Lemma 7 we know that player $j$ 's continuation payoffs are at most $(T-t)(1-$ $\left.\min \left(a_{i}, \frac{\epsilon_{i}}{T-t}\right)\right)$. By switching he pays $\epsilon_{j}$. Therefore, player $j$ never switches if $\frac{\epsilon_{j}}{T-t}>1-$ $\min \left(a_{i}, \frac{\epsilon_{i}}{T-t}\right)$. But it is easy to check that this inequality is now satisfied. Note that for $t>$ next $_{i}\left(t^{*}\right)$ we have that $\frac{\epsilon_{i}}{T-t}>\theta_{i}$ and $\frac{\epsilon_{j}}{T-t}>\theta_{j}$. With $a_{i} \geq \theta_{i}$ we have that $\frac{\epsilon_{j}}{T-t}>\theta_{j}=1-\theta_{i} \geq 1-\min \left(a_{i}, \frac{\epsilon_{i}}{T-t}\right)$. 
Lemma 8 Without loss of generality, let $t^{*} \in g_{i}$. In equilibrium, player $j$ plays $a_{j}^{\prime} \leq \theta_{j}$ at $\left(\left(\theta_{i}, a_{j}\right), \operatorname{next}_{j}\left(t^{*}\right)\right)$.

Proof If player $j$ plays $a_{j}^{\prime}>\theta_{j}$ then by Proposition 3 we know that none of the players will switch thereafter, the demands are not compatible, so continuation values are at most zero. By playing $a_{j}^{\prime}=\theta_{j}$, we know by Proposition 3 that none of the players will switch thereafter, the demands are now compatible, so continuation values are $\left(T-n e x t_{j}\left(t^{*}\right)\right) \theta_{j}$, which are equal to $\epsilon_{j}$. Thus, playing $\theta_{j}$ weakly dominates playing $a_{j}^{\prime}>\theta_{j}$. Player $j$ is indifferent if he sets $a_{j}^{\prime}=a_{j}>\theta_{j}$, but then we can assume that in such a case he also prefers to switch to $\theta_{j}$. If he does not, then the lemma would be true for any $a_{i}<\theta_{i}$ (but not for $a_{i}=\theta_{i}$ ) which would imply non-existence of equilibrium. Thus, the only equilibrium has player $j$ setting $a_{j}^{\prime} \leq \theta_{j}$.

Corollary 1 Player $i$, by playing $a_{i}=\theta_{i}$ at $t^{*}$ and never switching thereafter, can guarantee himself an agreement from next $t_{j}\left(t^{*}\right)$ on.

Proposition 4 Let the fineness of the grid satisfy $\varphi(g)<\min \left(\epsilon_{i}, \epsilon_{j}\right)$. Consider a subgame $\left(\left(\theta_{i}, a_{j}\right), t\right)$ for $t \leq t^{*}$ and $t \in g_{i}$. Player $i$ can guarantee himself continuation payoffs of $\theta_{i}\left(T-\right.$ next $\left._{j}(t)\right)$ by never switching.

Proof We prove it by induction on the game tree. The base is proved above for $t^{*}$ (Corollary 1). Suppose now that the proposition is true for next $(t)$ and we need to show it for $t$. By applying the induction assumption for player $i$ 's subsequent move (at next $t_{i}\left(\operatorname{next}_{t}(t)\right)$ ), we already know that $i$ can guarantee himself continuation value of $\theta_{i}\left(T-\operatorname{next}_{i}\left(\operatorname{next}_{\mathrm{f}}(t)\right)\right)$. Therefore, all we need to show is that player $j$ will accommodate immediately, namely that at $t^{\prime}=$ next $_{j}(t)$ player $j$ will play $a_{j}^{\prime} \leq \theta_{j}$. Note that if player $j$ plays $\theta_{j}$ at $t^{\prime}$, because of the induction assumption, his continuation value would be at least $\theta_{j}\left(T-t^{\prime}\right)-\epsilon_{j}$ : player $i$ will immediately accommodate, and agreement will be achieved already at $t^{\prime}$ because the demands are compatible.

We will now show that for player $j$ playing $\theta_{j}$ dominates not accommodating, namely setting $a_{j}^{\prime}>\theta_{j}$. Let $t^{\prime \prime}=\operatorname{next}_{i}\left(t^{\prime}\right)$ and $t^{\prime \prime \prime}=\operatorname{next}_{j}\left(t^{\prime \prime}\right)$. Let $v_{i}(s)$ be time $s$ continuation 
values for player $i$ on the equilibrium path of subgame $\left(\left(\theta_{i}, a_{j}^{\prime}\right), t^{\prime}\right)$. Using the induction assumption (for player $i$ at time $t^{\prime \prime}$ ), we have that $v_{i}\left(t^{\prime \prime \prime}\right) \geq \theta_{i}\left(T-t^{\prime \prime \prime}\right)$. For player $i$ to get this much, it must be that player $j$ (at $t^{\prime \prime \prime}$ or later) eventually changes his high demand of $a_{j}^{\prime}$. Let AllCosts Denote all switching costs spent (by both players) on the equilibrium path of $\left(\left(\theta_{i}, a_{j}^{\prime}\right), t^{\prime \prime \prime}\right)$. Because we know that player $j$ will eventually change his high demand, we can write AllCosts $=\epsilon_{j}+$ OtherCosts. Let also $a_{i}^{\prime}$ and $a_{i}^{\prime \prime}$ denote player $i$ 's equilibrium play at $\left(\left(\theta_{i}, a_{j}^{\prime}\right), t^{\prime \prime}\right)$ and at $\left(\left(\theta_{i}, \theta_{j}\right), t^{\prime \prime}\right)$, respectively.

Now, note that

$$
v_{i}\left(t^{\prime \prime \prime}\right)+v_{j}\left(t^{\prime \prime \prime}\right) \leq\left(T-t^{\prime \prime \prime}\right)-\text { AllCosts }=\left(T-t^{\prime \prime \prime}\right)-\epsilon_{j}-\text { OtherCosts }
$$

and thus

$$
\begin{aligned}
v_{j}\left(t^{\prime}\right) & =\left(t^{\prime \prime}-t^{\prime}\right) \pi_{j}\left(\theta_{i}, a_{j}^{\prime}\right)+\left(t^{\prime \prime \prime}-t^{\prime \prime}\right) \pi_{j}\left(a_{i}^{\prime}, a_{j}^{\prime}\right)+v_{j}\left(t^{\prime \prime \prime}\right) \leq \\
& \leq 0+\left(t^{\prime \prime \prime}-t^{\prime \prime}\right) \pi_{j}\left(a_{i}^{\prime}, a_{j}^{\prime}\right)+\left(T-t^{\prime \prime \prime}\right)-v_{i}\left(t^{\prime \prime \prime}\right)-\epsilon_{j}-\text { OtherCosts } \leq \\
& \leq\left(t^{\prime \prime \prime}-t^{\prime \prime}\right) \pi_{j}\left(a_{i}^{\prime}, a_{j}^{\prime}\right)+\left(T-t^{\prime \prime \prime}\right)-\theta_{i}\left(T-t^{\prime \prime \prime}\right)-\epsilon_{j}-\text { OtherCosts }= \\
& =\left(t^{\prime \prime \prime}-t^{\prime \prime}\right) \pi_{j}\left(a_{i}^{\prime}, a_{j}^{\prime}\right)+\theta_{j}\left(T-t^{\prime \prime \prime}\right)-\epsilon_{j}-\text { OtherCosts }
\end{aligned}
$$

where the first inequality arises from equation (13) and the second from the induction assumption. The last equality just uses the fact that $\theta_{i}+\theta_{j}=1$.

Now, we can finally check that this continuation value of $v_{j}\left(t^{\prime}\right)$ is lower than what $j$ would get by playing $\theta_{j}$ at $t^{\prime}$. By playing $a_{j}^{\prime}$ player $j$ gets

$$
v_{j}\left(t^{\prime}\right) \leq\left(t^{\prime \prime \prime}-t^{\prime \prime}\right) \pi_{j}\left(a_{i}^{\prime}, a_{j}^{\prime}\right)+\theta_{j}\left(T-t^{\prime \prime \prime}\right)-\epsilon_{j}-\text { OtherCosts }
$$

while by playing $\theta_{j}$ player $j$ gets

$$
\theta_{j}\left(T-t^{\prime}\right)-\epsilon_{j}=\theta_{j}\left(t^{\prime \prime \prime}-t^{\prime}\right)+\theta_{j}\left(T-t^{\prime \prime \prime}\right)-\epsilon_{j}
$$

The latter is greater as long as

$$
\theta_{j}\left(t^{\prime \prime \prime}-t^{\prime}\right) \geq\left(t^{\prime \prime \prime}-t^{\prime \prime}\right) \pi_{j}\left(a_{i}^{\prime}, a_{j}^{\prime}\right)-\text { OtherCosts }
$$

Now, if $\pi_{j}\left(a_{i}^{\prime}, a_{j}^{\prime}\right)=0$ we are done. If $\pi_{j}\left(a_{i}^{\prime}, a_{j}^{\prime}\right)>0$, this implies that player $i$ reduced his demand in period $t^{\prime \prime}$ (from $\theta_{i}$ to $a_{i}^{\prime}$ ), and thus OtherCosts $\geq \epsilon_{i}$. For a sufficiently fine grid (e.g. $\left.t^{\prime \prime \prime}-t^{\prime \prime}<\varphi(g)<\epsilon_{i}\right)$, the inequality of equation (17) holds, which finishes the proof. 
Proposition 5 Let the fineness of the grid satisfy $\varphi(g)<\frac{1}{2} \min \left(\epsilon_{i}, \epsilon_{j}\right)$. On the equilibrium path of the flow-payoff game each player $i$ demands $a_{i}^{*} \in\left(\theta_{i} \frac{T-2 \varphi(g)}{T}, 1-\theta_{j} \frac{T-2 \varphi(g)}{T}\right)$ the first time he plays and never switches thereafter.

Proof Without loss of generality, let next $(0)<\operatorname{next}_{j}(0)$. Let $t_{1}=\operatorname{next}_{j}(0)$ and $t_{2}=$ next $_{i}\left(\right.$ next $\left._{j}(0)\right)$. As the first decisions do not involve switching costs, player $i$ 's value of the game $v_{i}$ satisfies $v_{i} \geq \theta_{i}\left(T-t_{1}\right)$ and player $j$ 's value of the game $v_{j}$ satisfies $v_{j} \geq \theta_{j}\left(T-t_{2}\right)$. Note that $v_{i}+v_{j} \geq \theta_{i}\left(T-t_{1}\right)+\theta_{j}\left(T-t_{2}\right) \geq T-t_{2}>T-2 \varphi(g)$. It is now easy to see that there are no switches on equilibrium path: a switch implies that $v_{i}+v_{j}<T-\min \left(\epsilon_{i}, \epsilon_{j}\right)$, which is a contradiction. Without switching, it is clear that demands will be compatible starting at $n e x t_{j}(0)=t_{1}$ (the first time at which both players have demands). Thus, each player's demand $a_{i}^{*}$ must satisfy $\left(T-t_{1}\right) a_{i}^{*}=v_{i}$. This establishes the proof. Note that the bounds on demands are tighter once we know which player moves first. The lower bound for the first mover is $\theta_{i}$, making the upper bound for the second mover $1-\theta_{i}$.

At this point, all we need is to take limits of the result in Proposition 5 in order to finish the proof of Theorem 3 . 


\section{References}

[1] Admati, A. R., and M. Perry (1991), "Joint Projects without Commitment," Review of Economic Studies, 58, 259-276.

[2] Caruana, G., and L. Einav (2004), "A Theory of Endogenous Commitment," mimeo, Stanford University.

[3] Chae, S., and J. Yang (1988), "The Unique Perfect Equilibrium of an $n$-Person Bargaining Game," Economics Letters, 28, 221-223.

[4] Chae, S., and J. Yang (1994), "An n-Person Pure Bargaining Game," Journal of Economic Theory, 62, 86-102.

[5] Crawford, V. (1982), "A Theory of Disagreement in Bargaining," Econometrica, 50(3), 607-637.

[6] Gale, D. (2001), "Monotone Games with Positive Spillovers," Games and Economic Behavior, 37, 295-320.

[7] Haller, H. (1986), "Non-Cooperative Bargaining of $N \geq 3$ Players," Economics Letters, $22,11-13$.

[8] Herrero, M. (1985), “A Strategic Bargaining Approach to Market Institutions," Ph.D. Thesis, London School of Economics.

[9] Krishna, V., and R. Serrano (1996), "Multilateral Bargaining," Review of Economic Studies, 63(1), 61-80.

[10] Lensberg, T. (1988), "Stability and the Nash Solution," Journal of Economic Theory, $45,330-341$.

[11] Lipman, B., and R. Wang (2000), "Switching Costs in Frequently Repeated Games," Journal of Economic Theory, 93(2), 149-190.

[12] Lockwood, B., and J. P. Thomas (2002), "Gradualism and Irreversibility," Review of Economic Studies, 69(2), 339-357.

[13] Marx, L. M., and S. A. Matthews (2000), "Dynamic Voluntary Contribution to a Public Project," Review of Economic Studies, 67, 327-358. 
[14] Morelli, M. (1999), "Demand Competition and Policy Compromise in Legislative Bargaining," American Political Science Review, 93(4), 809-820.

[15] Muthoo, A. (1996), "A Bargaining Model Based on the Commitment Tactic," Journal of Economic Theory, 69, 134-152.

[16] Nash, J. (1950), "The Bargaining Problem," Econometrica, 18(2), 155-162.

[17] Perry, M., and P. J. Reny (1993), “A Non-cooperative Bargaining Model with Strategically Timed Offers," Journal of Economic Theory, 59, 50-77.

[18] Rubinstein, A. (1982), "Perfect Equilibrium in a Bargaining Model," Econometrica, $50,97-110$.

[19] Saloner, G. (1987), "Cournot Duopoly with Two Production Periods," Journal of Economic Theory, 42, 183-187.

[20] Selten, R. (1992), "A Demand Commitment Model of Coalitional Bargaining," in Rational Interaction Essays in Honor of John Harsanyi, R. Selten ed., Berlin: Springer Verlag, 245-282.

[21] Sutton, J. (1986), "Non-Cooperative Bargaining Theory: An Introduction," Review of Economic Studies, 53(5), 709-724.

[22] Winter, E. (1994a), "The Demand Commitment Bargaining: A Snowball in Cooperation," Economic Theory, 4, 255-273.

[23] Winter, E. (1994b), "Non-cooperative Bargaining in Natural Monopolies," Journal of Economic Theory, 64, 202-220.

[24] Yang, J. (1992), "Another $n$-Person Bargaining Game with a Unique Perfect Equilibrium," Economics Letters, 38, 275-277. 


\section{CEMFI WORKING PAPERS}

0101 Manuel Arellano: "Discrete choices with panel data".

0102 Gerard Llobet: "Patent litigation when innovation is cumulative".

0103 Andres Almazán and Javier Suarez: "Managerial compensation and the market reaction to bank loans".

0104 Juan Ayuso and Rafael Repullo: "Why did the banks overbid? An empirical model of the fixed rate tenders of the European Central Bank".

0105 Enrique Sentana: "Mean-Variance portfolio allocation with a Value at Risk constraint".

0106 José Antonio García Martín: "Spot market competition with stranded costs in the Spanish electricity industry".

0107 José Antonio García Martín: "Cournot competition with stranded costs".

0108 José Antonio García Martín: "Stranded costs: An overview”.

0109 Enrico C. Perotti and Javier Suárez: "Last bank standing: What do I gain if you fail?".

0110 Manuel Arellano: "Sargan's instrumental variable estimation and GMM".

0201 Claudio Michelacci: "Low returns in R\&D due to the lack of entrepreneurial skills".

0202 Jesús Carro and Pedro Mira: "A dynamic model of contraceptive choice of Spanish couples".

0203 Claudio Michelacci and Javier Suarez: "Incomplete wage posting".

0204 Gabriele Fiorentini, Enrique Sentana and Neil Shephard: "Likelihood-based estimation of latent generalised ARCH structures".

0205 Guillermo Caruana and Marco Celentani: "Career concerns and contingent compensation".

0206 Guillermo Caruana and Liran Einav: "A theory of endogenous commitment".

0207 Antonia Díaz, Josep Pijoan-Mas and José-Víctor Ríos-Rull: "Precautionary savings and wealth distribution under habit formation preferences".

0208 Rafael Repullo: "Capital requirements, market power and risk-taking in banking".

0301 Rubén Hernández-Murillo and Gerard Llobet: "Patent licensing revisited: Heterogeneous firms and product differentiation".

0302 Cristina Barceló: "Housing tenure and labour mobility: A comparison across European countries".

0303 Víctor López Pérez: "Wage indexation and inflation persistence".

0304 Jesús M. Carro: "Estimating dynamic panel data discrete choice models with fixed effects".

0305 Josep Pijoan-Mas: "Pricing risk in economies with heterogenous agents and incomplete markets".

0306 Gabriele Fiorentini, Enrique Sentana and Giorgio Calzolari: "On the validity of the Jarque-Bera normality test in conditionally heteroskedastic dynamic regression models".

0307 Samuel Bentolila and Juan F. Jimeno: "Spanish unemployment: The end of the wild ride?". 
0308 Rafael Repullo and Javier Suarez: "Loan pricing under Basel capital requirements".

0309 Matt Klaeffling and Victor Lopez Perez: "Inflation targets and the liquidity trap".

0310 Manuel Arellano: "Modelling optimal instrumental variables for dynamic panel data models".

0311 Josep Pijoan-Mas: "Precautionary savings or working longer hours?".

0312 Meritxell Albertí, Ángel León and Gerard Llobet: "Evaluation of a taxi sector reform: A real options approach".

0401 Andres Almazan, Javier Suarez and Sheridan Titman: "Stakeholders, transparency and capital structure".

0402 Antonio Diez de los Rios: "Exchange rate regimes, globalisation and the cost of capital in emerging markets".

0403 Juan J. Dolado and Vanessa Llorens: "Gender wage gaps by education in Spain: Glass floors vs. glass ceilings".

0404 Sascha O. Becker, Samuel Bentolila, Ana Fernandes and Andrea Ichino: "Job insecurity and children's emancipation".

0405 Claudio Michelacci and David Lopez-Salido: "Technology shocks and job flows".

0406 Samuel Bentolila, Claudio Michelacci and Javier Suarez: "Social contacts and occupational choice".

0407 David A. Marshall and Edward Simpson Prescott: "State-contingent bank regulation with unobserved actions and unobserved characteristics".

0408 Ana Fernandes: "Knowledge, technology adoption and financial innovation".

0409 Enrique Sentana, Giorgio Calzolari and Gabriele Fiorentini: "Indirect estimation of conditionally heteroskedastic factor models".

0410 Francisco Peñaranda and Enrique Sentana: "Spanning tests in return and stochastic discount factor mean-variance frontiers: A unifying approach".

0411 F. Javier Mencía and Enrique Sentana: "Estimation and testing of dynamic models with generalised hyperbolic innovations".

0412 Edward Simpson Prescott: "Auditing and bank capital regulation".

0413 Víctor Aguirregabiria and Pedro Mira: "Sequential estimation of dynamic discrete games".

0414 Kai-Uwe Kühn and Matilde Machado: "Bilateral market power and vertical integration in the Spanish electricity spot market".

0415 Guillermo Caruana, Liran Einav and Daniel Quint: "Multilateral bargaining with concession costs". 